\title{
Impact of Irrigation on Fertilizer Use Decision of Farmers in China: A Case Study in Weihe River Basin
}

\author{
Fanus Asefaw Aregay \\ College of Economics \& Management, Northwest A \& F University \\ 3 Taicheng Road, Yangling, Shaanxi 712100, China \\ Tel: 86-182-205-78157 Email: fanus_asie@yahoo.com \\ Zhao Minjuan (Corresponding author) \\ College of Economics \& Management, Northwest A \& F University \\ 3 Taicheng Road, Yangling, Shaanxi 712100, China \\ Tel: 86-152-893-83311 Email: minjuan.zhao@nwsuaf.edu.cn
}

Received: February 1, 2012 Accepted: March 5, $2012 \quad$ Published: April 1, 2012

doi:10.5539/jsd.v5n4p74

URL: http://dx.doi.org/10.5539/jsd.v5n4p74

The research is financed by China Ministry of Education's Project 20100204110031

\begin{abstract}
The contribution of irrigation and chemical fertilizer on Chinese agricultural production growth is considerable. Both subsidized fertilizer price and low irrigation water price have encouraged farmers to adopt these modern inputs. However, the inefficient usages practiced by the farmers have exposed the nation to environmental and water pollution. Moreover, the increasing production cost arising from overuse of fertilizer coupled with decreasing soil response to fertilizer application is another issue. The Chinese government has proposed integrated water management plans like irrigation water pricing to regulate the co-existing problems. There are enough evidences that adoption of irrigation can induce adoption of inorganic fertilizer. However, researches on their relationship are scant in areas where inefficient utilization of these inputs is the problem rather than their adoption. Thus, the main objective of this paper was to analyze whether irrigation have a significant impact on fertilizer use decision of farmers in China. Our case study in Shaanxi province along the Weihe River basin based on farm plot level primary data confirmed that fertilizer use have a significant relationship with irrigation. From our analysis using ordinary least square model, we concluded that policies that improve irrigation water efficiency could also have impact on fertilizer use efficiency.
\end{abstract}

Keywords: Inorganic fertilizer, Irrigation water, Inefficiency, Ordinary Least Square Model, Weihe River

\section{Introduction}

The fact that adequate water and nutrient availability in the soil are necessary conditions for sustainable agricultural growth has motivated the Chinese government to devote considerable efforts on supplementing the soil with irrigation water and fertilizer. The modern irrigation expansion from 15.4 million hectares in 1949 to 57 million hectares in 2004 and increase in nitrogen fertilizer consumption by 271 percent between 1977 and 2005 are clear evidences (Amarasinghe et al., 2005; Shwartz, 2009; Kahrl et al., 2010). China now accounts for the largest irrigated areas and dominates global consumption of fertilizer.

Chinese farmers have simultaneously increased application of fertilizer and irrigation since 1960's, which have played a considerable role in agriculture on the nation (IFPRI, 2002; Frolking et al., 1999). Irrigated agriculture is now producing about $75 \%$ of the cereals, $90 \%$ of cotton, fruits, vegetables and other agricultural commodities, in about $42 \%$ of the farmland with a significant contribution of fertilizer on improving the productivity (Li, 2006; Liu \& Wang, 2005). These two inputs are complementary inputs where fertilizer works more effectively in the presence of sufficient water in the soil (Li et al., 2004). This is because irrigation prevents water stress situation and help for absorption of fertilizer nutrients by plant roots either through mass flow or through diffusion mechanisms. However, unfavorable situation can occur when either of these inputs is used inefficiently. 
Concerns about the inefficient usage of fertilizer and irrigation water are currently high in China. Chinese agriculture is considered as a major polluter, sending over 13 million tons of effluent including fertilizers and pesticides into waterways each year (Sonja, 2011). Moreover, farmers are incurring unnecessary production cost by overusing fertilizer as well as negatively affecting their farmland's response to fertilizer (Huang, 2010; Williams, 2005; Esbestein et al., 2011). Sonja (2011) has reported that fertilizer use in China can be reduced by $20-30 \%$ without loss of yield subjective to the improvement in fertilizer use efficiency. The low irrigation water efficiency is also aggravating overflow of pollutants. Different bodies have stated that about 60 percent of the irrigation water is being wasted by evaporation and percolation, leaching soil nutrients and chemicals while water scarcity is prevalent in the nation (Xinhua News Agency, 2001; Yang et al., 2004; Lonmar et al., 2003). Thus, how to promote the efficient utilization of these inputs is the current issue in China. Chinese government is taken river basin specific water management plans, which include irrigation water pricing, but its impact on fertilizer application depends on whether irrigation is a determinant factor on fertilizer use decision of farmers.

Some literatures have argued that the adoption of irrigation to overcome the shortage of water to crops has induced the adoption of fertilizer, which is more productive under sufficient water (Fufu \& Hassen, 2006; Wakeyo \& Gardebroaek, 2011). Different case studies on impact of irrigation on fertilizer use found out that the extent and intensity of fertilizer use was higher in irrigated plots than in rain fed plots (Gebrezgabher \& Holden, 2011; Wakeyo \& Gardebroaek, 2011; Yilma \& Berger, 2006). Moreover, positive influence of irrigation water on fertilizer productivity was proved in different researches. For example, Li et al. (2004) investigation on irrigation and fertilizer effect on wheat yield response in semi-arid region of China found out that fertilizer productivity was better in irrigated farming than in rain fed farming.

Nevertheless, China has reached the contrary story. The adoption of these modern inputs is no more a point of concern. On the other hand, solving the problems arising from inefficient utilization of these inputs is the issue. Researches on the relationship between irrigation and fertilizer use, in areas where farmers have already adopted these inputs but over utilized them, are scant. Thus, this paper attempted to investigate whether irrigation water use has a significant relationship with fertilizer use decision of farmers to contribute an evidence for policy maker to implement appropriate solution to the two co-existing problems. To analyze this issue, a case study was taken in Shaanxi province of China in Guanzhong irrigation region along the weihe river basin. This river basin is typical sample for it is suffering from water pollution and water shortage while playing a vital role in agricultural and economic development of Shaanxi province in particular and China in general. A farm level primary data on fertilizer use, irrigation use, household characteristics, farm characteristics, and other variables for the production year 2010 was collected using a predefined questionnaire. Then, we employed a general ordinary least square model for analysis.

This paper is organized as follows. Methodology is the next section followed by description of the Case study area and data. Then, result \& discussion occupy the fourth. Finally, the last section is conclusion. References and tables are also included at the end of the article.

\section{Methodology}

This section presents the conceptual framework and estimation approach of the paper.

To examine whether irrigation has significant effect on farmers investment decision on fertilizer, a linear regression analysis was carried-out based on the primary data collected from four counties and two administrative districts along the Weihe river basin in Shaanxi province of china. The fact that all the sample plots had received fertilizer during the 2010 production year, conventional ordinary least square model (OLS), a commonly used model in dealing with households' input use decision issues was adopted (Yilma \& Berger, 2006; Zhou et al., 2010). Variables such as farm average income, farm and farmers characteristics, and inorganic fertilizer's complementary and substitution inputs were included as explanatory variables. Before the final analysis, the data was tested to find whether it had a normal distribution or not. A preliminary test was also undertaken for model misspecification and explanatory variables multi-collinearity. Then, the empirical model was specified as:

$\ln \mathrm{F}_{\mathrm{i}}=\alpha_{\mathrm{i}}+\pi \mathrm{X}_{\mathrm{ir}}+\beta \mathrm{X}_{\mathrm{ij}}+\gamma \mathrm{X}_{\mathrm{il}}+\delta \mathrm{X}_{\mathrm{ic}}+\eta \mathrm{X}_{\mathrm{is}}+\varepsilon_{\mathrm{i}} \quad \quad \varepsilon_{\mathrm{i}} \sim \mathrm{N}\left(0 . \sigma_{\varepsilon}^{2}\right)$

Where

$\ln \mathrm{F}_{\mathrm{i}}=$ logarithmic form of inorganic fertilizer cost invested in plot "i" by the individual household. Since the farmers used different types of inorganic fertilizers, the average inorganic fertilizer cost per ha for the particular plot inquired in the year 2010 ( two seasons of production or three cycles in some vegetable grown plots) viewed as a dependent variable in the analysis. 
$\alpha_{\mathrm{i}}=$ intercept for plot "i”".

$\mathrm{X}_{\mathrm{ir}}=$ average income per ha of farm "i" in 2010 production year.

$X_{i j}=$ household characteristics. From the household characteristics variables, head of household's age, household agricultural labor, and 2009 annual income was considered in their logarithmic form.

$\mathrm{X}_{\mathrm{il}}=$ characteristics of farm plot "i".

$\mathrm{X}_{\mathrm{ic}}=$ dummy irrigation use in plot "i".

$X_{\text {is }}=$ organic fertilizer use in plot ' $i$ ' in 2010 production year.

$\varepsilon_{\mathrm{i}}=$ random variable.

$\pi, \beta, \delta$, and $\eta=$ regression coefficients.

The expectations on the correlation between the dependent variable (inorganic fertilizer cost per ha) and the explanatory variables are as follows.

Average farm income: The demand of an input depends on its productivity. Fertilizer enhances productivity assuming that other complementary inputs are in place. Since the sample plots were planted with different types of crops, annual gross revenue per hectare was included in the analysis in order to account for the output level and price of the product. Positive sign is expected between fertilizer use and the average revenue per hectare (Abdoulaye \& Sanders, 2005).

\section{Household characteristics:}

Head of household's age: Farmers may gain management experience through time. They probably learn more on inputs application and their expected returns. On the other hand, older farmers are conservative and reluctant to adopt new technologies for fear of risk associated with it (Fufu \& Hassen, 2006). Hence, head of household's age have undetermined relation with fertilizer use.

Head of household's education level: Several studies have suggested that the more educated a farmer is, the more he/she will adopt modern inputs (Croppenstedt et al., 2003). We expect similar finding for education.

Family size: It is proved that fertilizer application increases productivity. Thus, household with a large family size may tend to use productive inputs like fertilizer to boost production in order to fulfill the family needs. However, fertilizer acquisition needs money, which otherwise the family could use to buy other household necessities (Wakeyo \& Gardebroaek, 2011; Zhou et al., 2010). In this case, large family size may be reluctant to invest in fertilizer because of the competing needs. Therefore, the impact of family size on fertilizer use is ambiguous.

Agricultural labor: The expected effect of household agricultural labor on fertilizer application is negative. This is because fertilizer enhances healthy growth of the crops, diminishes growth of weeds and in turn decrease labor required for weeding. This means that families with less labor are expected to use more fertilizer.

Off-farm work: Some studies found out that off-farm work have positive impact on fertilizer use (Ebenstein et al., 2011; Yilma \& Berger, 2006). Farmers who take additional work other than agriculture either in the off production season or who leave the responsibility of agricultural work to other members of the family may become financial more capable to buy fertilizer input. They may also tend to overcome the possible effect of their absence on output by applying more fertilizer. On the other hand, farmers who get large proportion of their income from off-farm employment can possibly neglect their farms and invest less on productive inputs. Moreover, those farmers who mainly earn their income from agricultural activity can cultivate profitable crops such as vegetables, which demand investment on modern inputs. Therefore, the relationship between off-farm work and fertilizer use is ambiguous.

Household annual income: Household annual income is considered in order to account for the capital endowment of the farmers. Households with higher annual income have more capacity to invest in fertilizer. Because the availability of sufficient money increases the probability to buy productive inputs, positive relationship is expected.

Farm characteristics:

Farm size: The effect of farm size on fertilizer use is uncertain. Some studies have shown positive relationship between the probability of adoption fertilizer and plot size, while negative relationships in case of fertilizer use intensity (e.g., Gebrezgabher \& Holden, 2011). In some cases, farmers may utilize their small sized farm in a more productive manner to attain the maximum yield in order to satisfy the household needs. In other cases, 
when the farmer have alternative source of income, it is possible to neglect their small sized farms and concentrate their efforts on other more productive alternative jobs. They may not invest on fertilizer if the harvest is not remunerative (Yilma \& Berger, 2006).

Crop type: Fertilizer use may differ with crop choice. In this case, we hypothesize that fertilizer application is higher in vegetable crops. As vegetable production cycle is shorter, a plot can be cultivated more frequently and more nutrients be removed from the soil each year. So the yearly fertilizer use is expected to be higher in plots planted vegetable.

Soil type: The impact of soil type on fertilizer use is undetermined. Rational farmers make decision on input use based on the expected marginal returns. They are likely to use less fertilizer on fertile soils as the marginal return on additional fertilizer is low. On the other hand, for instance clay soil, which is more fertile, may tolerate the fertilizer even in low soil moisture times while fertilizer on sand soil may burn the crops if there is insufficient soil moisture. Thus, the relationship is ambiguous.

Complementary inputs:

Irrigation water: Irrigation water is a complementary input to fertilizer. Irrigation water adds moisture to the soil and improves the diffusion of nutrients. Irrigation increases the absorption of inorganic nutrients by plant roots. For this reason, farmers use irrigation water to overcome water shortages to enhance nutrients absorption. Therefore, we assume positive impact of irrigation use on fertilizer application. Some studies have also found similar effect (Fufu \& Hassen, 2006; Gebrezgabher \& Holden, 2011; Wakeyo \& Gardebroaek, 2011).

Substitute Inputs:

Organic fertilizer: Farmers of this region have the access to buy organic fertilizer and it is worth considering organic fertilizer in the analysis. We hypothesize negative relationship, as inorganic fertilizer and organic fertilizer are substitute inputs to each other.

\section{Case Study Area and Data Description}

This section presents the general description of the case study area and presents the summary of the data used in the analysis.

A case study was carried out in the Guanzhong irrigation region along Weihe River basin within Shaanxi province. Weihe River is the largest tributary of the Yellow River. This river basin is known as mother of Shaanxi province for it has played very important role in the development of Shaanxi province since ancient times. Almost half $(49.7 \%)$ of the total area coverage of the basin $\left(135000 \mathrm{~km}^{2}\right)$ lies in Shaanxi province. It annually generates 6.992 billion $\mathrm{m}^{3}$ volume of water. This river runs from west to east through Baoji, Yangling, Xianyang, Xi'an and Weinan -5 cities in Shaanxi province, across the Guanzhong plain. The population in the river basin reaches around 22 million which is $61 \%$ of the total population of Shaanxi; and a cultivated area of 1 665000 hectares (56\% of the whole), with irrigated areas covering 950000 hectares ( $72 \%$ of total irrigated area). Indeed, the area plays a crucial strategic role in the China Western Development Program. However, with the fast economic development in Weihe River Basin in recent years, many problems have arisen. These include increasing water resources scarcity, water pollution and regional ecological environment deterioration.

For its important role in agricultural and economic development of China, plot level primary data was collected along this river basin from sample farms in Dali County, Hua County and Linwei District of Weinan prefecture city; Wugong County, Yangling District of the Xianyang prefecture city and Fufeng county of Baoji prefecture city in Shaanxi province. Out of eighteen villages selected randomly from these six counties, 100 farm plots of different households were systematically chosen to include commonly cultivated cereal (wheat and maize) and vegetables (Tomato, watermelon, Chinese cabbage, Garlic, Cucumber, cowpea and green vegetables). The survey was conducted from June to September in 2011. Finally, 87 of the sample plots qualified for the analysis as the other $13 \mathrm{had}$ insufficient information. The plots are of four types in terms of water source for production. They include exclusively rain fed, rainfall based (use irrigation water in extreme drought), irrigation based (mainly rely on irrigation water) and exclusively irrigated plots. However, we classified them into two groups; rain fed plots (exclusively rain fed) and irrigated plots that encompass the other three categories in order to include it as a binary variable in the analysis.

All the sample farmers had applied inorganic fertilizer in 2010 production year. The mean inorganic fertilizer cost was 6741.47 Yuan/ha. Yet, the mean inorganic fertilizer cost under irrigated plots was almost twice as the inorganic fertilizer cost in rain fed plots. In most cases, the farmers plant either cereal (wheat and maize) in alternative season, or different vegetables throughout the year. Rain fed plots were mostly cereal crops, whereas, both cereals and vegetables were cultivated under irrigation. In the sample plots considered, irrigated plots were 
planted vegetables $(60.9 \%)$ and cereals $(39.1 \%)$, while $83.3 \%$ of non-irrigated plots were cereal crops and only $16.7 \%$ were vegetables. This may imply that the fertilizer use decision of farmers mostly depend on the crop planted while the cropping choice may depend on availability of irrigation. The summary of the mean inorganic fertilizer cost for different crops and the description of the data for all the variables considered in the analysis are at the end of the article in Table 1 and 2 respectively.

\section{Results and Discussion}

The result of OLS analysis with average inorganic fertilizer cost per hectare as dependent variable is presented in Table 3. The result was consistent with our hypothesis. All the signs of correlation were as expected except for crop type. Coefficient of dummy irrigation use variable was also significant.

As it is vividly depicted in Table 3, irrigation, average farm income and head of household education level showed positive and significant coefficients. These variables have the probability of driving fertilizer use in the same direction when they change. While plot size, organic fertilizer, and off-farm work carried negative and significant coefficients implies that these variables have potential effect to reduce fertilizer application when they increase or vice versa. Education and family size have positive but insignificant coefficients. Whereas, crop type, head of household age, agricultural labor and soil type carried negative and insignificant coefficient.

The main objective of this paper was to examine whether irrigation use has a significant impact on fertilizer application. According to the regression result, there is a strong positive correlation between the investment on fertilizer and irrigation use. From the analysis, we are 95\% confident that irrigation has a significant impact on farmer's decision on inorganic fertilizer utilization. Relative to non-irrigated plots, irrigated plots received 42 percent higher inorganic fertilizer if the other variables in the model remain constant. This implies that any policy that improves the irrigation water efficiency will also have a potential to improve the fertilizer use efficiency.

Other variables also seemed to be important determinants of farmer's investment on fertilizer. Average farm income was significant at $95 \%$ significance level. Based on the regression coefficient of average farm income, an additional 1-Yuan farm income would increase investment on inorganic fertilizer by 0.0037 percent. This implies that farmers make investment decision on modern inputs based on their expected productivity. Similarly, earning of high income from their previous harvest may strengthen their capital resource acquisition and improves their purchasing power for modern inputs like fertilizer. Likewise, head of household education level was significant at $90 \%$ significance level. One-year difference in education level induces $3.2 \%$ increment in inorganic fertilizer investment. This indicates that education enhances the management and decision making skill of farmers, therefore, they tend to invest more on modern productive inputs.

Moreover, organic fertilizer, farm size, off-farm work, and agricultural labor with $99 \%, 99 \%, 95 \%$, and $95 \%$ significance level respectively showed significant negative relationship with investment on inorganic fertilizer. According to the regression result, a 1-Yuan additional investment on organic fertilizer leads to 0.0037 percent decrease on inorganic fertilizer investment keeping other variables constant. Indeed, a preliminary analysis of our primary data disclosed that some farmers were applying both inorganic fertilizer and organic fertilizer. All of the plots, which received organic fertilizer, were irrigated plots under vegetable cultivation. Moreover, the data clearly indicates, those farmers who used both organic and inorganic fertilizer invest less on inorganic fertilizer than those who applied only inorganic fertilizer. This trend is rational as organic fertilizer is a close substitute input for inorganic fertilizer. For off-farm work, those farmers who had additional work tended to invest 28.6 percent less inorganic fertilizer than those farmers who devote their full time on farming. The reason behind this phenomenon is probably that farming contributes less to the total income of farmers who take off farm work, thus they neglect investment on modern farm inputs. Likewise, 1-hectare increase in plot size tends to decrease the investment on fertilizer by $0.7 \%$ percent. The average land holding in China is generally small equals to 0.67 ha. In our case, the mean farm size was 0.181 ha since we consider single plot level information. The farmers generally do not have enough farmland that can satisfy their family needs. Therefore, farmers with smaller sized farm to (cancel to) intensify their farming and invest more on productive inputs to attain the maximum yield possible. Moreover, the negative relationship between household agricultural labor availability and fertilizer use is predictable. This is so because fertilizer can enhance healthy growth of crops, diminish growth of weeds and thus decrease labor required for weeding. So families with less labor tend to use more fertilizer. According to the analysis result, a $1 \%$ increase in the household agricultural labor would decrease inorganic fertilizer application by $0.117 \%$. 


\section{Conclusion}

Irrigation and fertilizer use are playing an indispensible role in agricultural growth of China. However, inefficient use of these inputs by Chinese farmers is resulting in increased production cost, downward response of soil to fertilizer application, and aggravated environmental and water pollution. Farmers are being claimed for overusing fertilizer and for being reluctant to take steps to reduce it. To overcome the concurrent problems, the Chinese government has proposed integrated water management plans, which includes increasing irrigation water price in the recent years. But the impact of irrigation water pricing on fertilizer use efficiency depends mainly on the significant relationship between these two factors of production. Therefore, this paper was aimed to analyze the relationship between irrigation use and fertilizer use decision of farmers in order to examine whether the proposed plan will have an effect on fertilizer use as well. Our analysis based on a primary data from 87 farm plots along the Weihe River basin showed that irrigation use and inorganic fertilizer application are highly correlated. According the result, irrigation water use was a significant determinant of fertilizer use decision of farmers. Therefore, we conclude that policies that improve irrigation water efficiency can have a potential to positively influence fertilizer use efficiency.

\section{References}

Abdoulaye, T., \& Sanders, J. H. (2005). Stages and determinants of fertilizer use in the semiarid agriculture: Niger experience. Agricultural Economics, 32, 167-179. http://dx.doi.org/10.1111\%2Fj.0169-5150.2005.00011.x

Amarasinghe, U. A., Giordano, M., Liao, Y., \& Shu, Z. (2005). Water supply, water demand and agricultural water scarcity in China: A basin approach [CPSP Report 11]. New Delhi, India: International commission on drainage \& irrigation (ICID) Available: www.iwmi.cgiar.org/.../ICID_China_A_Basin\%20Approach.pdf (Oct. $10,2010)$

Croppenstedt, A., Demeke, M., \& Meschi, M. M. (2003). Technology adoption in the presence of constraints: The case of fertilizer demand in Ethiopia. Review of Development Economics, 7 (1), 58-70. http://dx.doi.org/10.1111\%2F1467-9361.00175

Ebenstein, A., Zhang, J., McMillan, M., \& Chen, K. (2011). Chemical Fertilizer and Migration in China (NBER Working Paper No. 17245). Cambridge, MA: The National Bureau of Economic Research (NBER). [Online] Available: http://www.nber.org/papers/w17245 (Dec 10, 2011)

Frolking, S., Xiao, X., Zhuang, Y., Salas, W., \& Li, C. (1999). Agricultural land use in China: A comparison of area estimates from ground-based census and satellite-borne remote sensing. Global Ecology and Biogeography, 8, 407-416. http://dx.doi.org/10.1046/j.1365-2699.1999.00157.x

Fufu, B., \& Hassen, R. M. (2006). Determinants of fertilizer use on maize in eastern Ethiopia: A weighted endogenous sampling analysis of the extent and intensity of adoption. Agrekon, 45 (1), 38-49. http://dx.doi.org/10.1080\%2F03031853.2006.9523732

Gebregziabher, G., \& Holden, S. (2011). Does irrigation enhance and food deficits discourage fertilizer adoption in a risky environment: Evidence from Tigray, Ethiopia. Journal of Development and Agricultural Economics, 3 (10), 514-528. [Online] Available: http://www.academicjournals.org/JDAE/

Harris, D. (2004). Water and nitrogen management in wheat-maize production on the north China plain [Impact Assessment Series Report No. 28]. Canberra, Australia: Australian centre for international agricultural research. [Online] Available: http://aciar.gov.au/ (Nov 10, 2011)

Huang, Y., Sass, R.L., Sun, W., Zhang, W., \& Yu, Y. (2010). Reducing nitrogen fertilizer use to mitigate negative environmental impact in China. Houston, TX: James A. Baker III institute for public policy. [Online] Available: http://bakerinstitute.org/publications/GCC-pub-HuangSassReducingNitrogenChina-122210.pdf

International Food Policy Research Institute. (2002). Green revolution curse or blessing? International food policy research institute: Sustainable options for ending hunger and poverty, Washington, DC. [Online] Available: http://www.ifpri.org/

Kahrl, F., Li, Y., Su, Y., Tennigkeit, T., Wilkes, A., \& Xu, J. (2010). Greenhouse gas emissions from nitrogen fertilizer use in China. Environmental Science \& Policy, 13, 688-694. http://dx.doi.org/10.1016/j.envsci.2010.07.006

Kahrl, F., Yunju, L., Roland-Holst, D., Jianchu, X., \& Zilberman, D. (2010). Toward sustainable use of nitrogen fertilizers in China. University of California Giannini Foundation of Agricultural Economics: ARE update, 14 (2), 5-7. [Online] Available: http://giannini.ucop.edu/ 
Li, H. (2006). Strategies for coping with water scarcity in China. [Online] Available: http://www.unwater.org/downloads/wwwyuananhua.pdf (Nov. 10, 2010)

Li, W., Li, W., \& Li, Z. (2004). Irrigation and fertilizer effects on water use and yield of spring wheat in semi-arid regions. Agricultural Water Management, 67 (1), 35-46. http://dx.doi.org/10.1016/j.agwat.2003.12.002

Liu, Y., \& Wang, X. (2005). Technological progress and Chinese agricultural growth in the 1990s. China Economic Review, 16, 419-440. http://dx.doi.org/10.1016/j.chieco.2005.03.006

Lohmar, B., Wang, J., Rozelle. S., Huang, J., \& Dawe, D. (2003). China's agricultural water policy reforms: increasing investment, resolving conflicts, and revising incentives [Agriculture information bulletin 782]. U.S. Department of Agriculture Economic Research Service.

Shwartz, M. (2009). Study highlights massive imbalances in global fertilizer use [News report]. Stanford University news. [Online] Available: http://news.stanford.edu/news/2009/june24/massive-imbalances-in-global-fertilizer-use-062209.html (Nov. 10, 2011)

Sonja. (2011). Fertilizing grounds for change for Chinese agriculture [News bulletin]. Climate change: Agricultural and food security. [Online] Available: http://ccafs.cgiar.org/resources/agclim-letters-policy-bulletin (Nov. 20, 2011)

Wakeyo, M. B., \& Gardebroek, C. (2011). The impact of water harvesting irrigation on fertilizer use in Ethiopia. [Online] Available: www.aep.wur.n1/NR/rdonlyres/D3255A0B.../102_Wakeyo.pdf (Nov. 10, 2011).

Williams, J. (2005). Understanding the overuse of chemical fertilizer in China: A synthesis of historic trends, recent studies, and field experiences. [Online] Available: http://forestry.msu.edu/china/new\%20folder/jo_fertilizer.pdf (Nov. 2, 2011)

Xinhua News Agency. (2001). China plans to promote efficient irrigation. [Online] Available: http://www.china.org.cn/english/BAT/16483.htm (Nov. 20, 2010)

Yang, D., Li, C., Hu, H., Lei, Z.,Yang, S., Kusuda,T., Koike, T., \& Musiake, K. (2004). Analysis of water resources variability in the Yellow River of China during the last half century using historical data. Water Resource Research, 40. http://dx.doi.org/10.1029/2003WR002763

Yilma, T., \& Berger, T. (2006). Complementarily between irrigation and fertilizer technologies: A justification for increased irrigation investment in the less-favored areas of SSA. Contributed paper prepared for presentation at the International Association of Agricultural Economists Conference, Gold Coast, Australia. [Online] Available: http://ageconsearch.umn.edu/bitstream/25701/1/cp060763.pdf (Nov. 30, 2011)

Zhou, Y., Yang, H., Abbaspour, K. C., \& Mosler, H-J. (2010). Factors affecting farmers' decisions on fertilizer use: A case study for the Chaobai Watershed in northern China. Consilience: The journal of sustainable development, 4 (1), 80-102. [Online] Available: http://consiliencejournal.org/

Table 1. Mean inorganic fertilizer cost (Yuan/ha) on irrigated and non-irrigated plots in 2010 production year

\begin{tabular}{ccccc}
\hline & \multicolumn{2}{c}{ Irrigated } & Non-irrigated \\
\hline Crop type & No. of plots & Mean fertilizer cost & No. of plots & Mean fertilizer cost \\
vegetables & 42 & 9242.96 & 3 & 5686.5 \\
cereals & 27 & 4667.67 & 15 & 3681.1 \\
total & 69 & 7452.63 & 18 & 4015.33 \\
\hline
\end{tabular}


Table 2. Descriptive statistics of the variables used in the prediction

\begin{tabular}{|c|c|c|c|c|}
\hline & Minimum & Maximum & Mean & Std. Deviation \\
\hline Inorganic fertilizer $\operatorname{cost}^{\mathrm{a}}($ Yuan/ha) & 1929 & 28080 & 6741.50 & 5606.804 \\
\hline Head of household's age & 23 & 78 & 50.16 & 10.371 \\
\hline $\begin{array}{c}\text { Head of household's education } \\
\text { level }\end{array}$ & 1 & 12 & 7.63 & 3.239 \\
\hline $\begin{array}{c}\text { Dummy crop variable; vegetable }=1 \text {, } \\
\text { cereal }=0\end{array}$ & 0 & 1 & 0.52 & 0.503 \\
\hline Farm size(ha) & 0.04 & 0.67 & 0.1828 & 0.125 \\
\hline Family size & 2 & 9 & 4.91 & 1.378 \\
\hline Agricultural labor ${ }^{\mathrm{b}}$ & 1 & 6 & 2.46 & 1.054 \\
\hline $\begin{array}{l}\text { Dummy irrigation variable; } \\
\text { irrigated }=1 \text {, non-irrigated }=0\end{array}$ & 0 & 1 & 0.79 & 0.407 \\
\hline Organic fertilizer(Yuan/ha) & 0 & 18000 & 2786.2 & 15127.77 \\
\hline Annual income ${ }^{\mathrm{c}}$ (Yuan) & 2500.0 & 70000 & 27267 & 15127.77 \\
\hline Average farm income ${ }^{d}$ & 15037.50 & 375000 & 114960 & 6674.38 \\
\hline Off-farm work ${ }^{\mathrm{e}}$ yes $=1$, & 0 & 1 & .52 & .502 \\
\hline Soil type; loess $=0$, otherwise $=1$ & 0 & 1 & 0.14 & 0.347 \\
\hline Valid number (list wise) & 87 & & & \\
\hline
\end{tabular}

a. The average fertilizer cost per hectare the particular plot inquired for the year 2010.

b. Agricultural labor represents for the household members above 14 years old who involve in the farming activities.

c. Annual income accounts for total income of the household got from both agricultural and non-agricultural activities in the preceding year.

d. Average farm income per ha corresponds to the gross revenue from the sale of the output of the particular plot under consideration for the year 2010 before any cost is deducted.

e. Off-farm work represents whether the head of household takes job other than in his own plot. 
Table 3. The OLS regression result for $\ln$ (average inorganic fertilizer cost) in Yuan/ha as dependent variable (standard errors in parenthesis)

\begin{tabular}{ccc}
\hline Explanatory variables & Coefficients \& std. errors & t-statistics \\
Constant & $7.684^{* * *}(1.392)$ & 5.52 \\
Dummy irrigation & $0.421^{* *}(0.183)$ & 2.294 \\
Soil type & $-0.111(0.185)$ & -0.601 \\
Off-farm work & $-0.286^{* *}(0.124)$ & -2.304 \\
Cost of organic fertilizer per ha & $-0.000037^{* * *(0.000)}$ & 2.965 \\
Average farm income per ha & $0.000037^{* *}(0.000)$ & 2.017 \\
ln(annual income) & $0.167(0.122)$ & 1.367 \\
Crop type & $-0.133(0.251)$ & -0.529 \\
Farm size in ha & $0.007 * * *(0.003)$ & -2.904 \\
Head of household education & $0.032^{*}(0.018)$ & 1.758 \\
level & $-0.117^{* *}(0.166)$ & -2.059 \\
$\ln ($ agricultural labor $)$ & $-0.178(0.177)$ & 0.319 \\
$\ln ($ head of household age $)$ & $-0.016(0.045)$ & -0.353 \\
Family Size & & 0.524 \\
Std. error of estimate & & $4.969 * * *$ \\
F & & 0.446 \\
$\mathrm{R}^{2}$ & & 0.356 \\
Adjusted $\mathrm{R}^{2}$ & & $>0.1$ \\
Tolerance & & -0.0024 \\
Skewness & & 0.001 \\
Kurtosis & &
\end{tabular}
a. Dependent Variable: average inorganic fertilizer cost per ha;
b. $\quad * * * \mathrm{P}<0.01, * * \mathrm{P}<0.05, * \mathrm{P}<0.1$
c. The t-statistics, coefficients and std errors are obtained from SPSS analysis. 